\title{
Arterial stiffness in children with primary hypertension is related to subclinical inflammation
}

\author{
PIOTR SKRZYPCZYK ${ }^{1}$, ANNA ZACHARZEWSKA², MICHAE SZYSZKA ${ }^{3}$, ANNA OFIARA ${ }^{1}$, \\ MALGORZATA PAŃCZYK-TOMASZEWSKA ${ }^{l}$ \\ ${ }^{1}$ Department of Pediatrics and Nephrology, Medical University of Warsaw, Poland \\ ${ }^{2}$ Student Scientific Group at the Department of Pediatrics and Nephrology, Medical University of Warsaw, Poland \\ ${ }^{3}$ Department of Pediatrics and Nephrology, Doctoral School, Medical University of Warsaw, Poland
}

\begin{abstract}
Introduction: The immune system can trigger an inflammatory process leading to blood pressure elevation and arterial damage. The aim of the study was to assess the relation between subclinical inflammation and arterial damage in pediatric patients with primary hypertension $(P H)$ and to establish the usefulness of neutrophil-to-lymphocyte (NLR) and platelet-to-lymphocyte (PLR) ratios, and mean platelet volume $(M P V)$ as markers of arterial damage in these subjects.

Material and methods: In 119 children with PH (14.94 \pm 2.76 years) and 45 healthy children (14.91 \pm 2.69 years) we analyzed markers of subclinical inflammation (NLR, PLR, MPV), clinical and biochemical parameters, office blood pressure, ambulatory blood pressure monitoring (ABPM), central blood pressure, aortic pulse wave velocity $(a P W V)$, augmentation index corrected for heart rates 75 (AIx75HR), carotid intima media thickness (cIMT), and common carotid artery stiffness (E-tracking).

Results: Children with PH were characterized by significantly higher neutrophil ( $3.9 \pm 1.7$ vs. $3.0 \pm 1.0[1000 / \mu \mathrm{l}], p<0.001)$ and platelet counts $(271.9 \pm 62.3 \mathrm{vs} .250 .3 \pm 60.3[1000 / \mu \mathrm{l}]$, $p=0.047), N L R(1.9 \pm 1.5$ vs. $1.3 \pm 0.4, p=0.010), P L R(131.4 \pm 41.9 v s .114 .7 \pm 37.6, p=0.020), a P W V$ $(5.36 \pm 0.88 v s .4 .88 \pm 0.92 \mathrm{~m} / \mathrm{s}, p=0.004)$, and cIMT $(0.46 \pm 0.07 v s .0 .43 \pm 0.07 \mathrm{~mm}, p=0.002)$ compared to healthy children. In PH children NLR correlated positively $(p<0.05)$ with: systolic, diastolic and mean blood pressure in ABPM $(r=0.243, r=0.216, r=0.251), a P W V[m / s](r=0.241), a P W V$ $Z$-score $(r=0.204)$, and common carotid artery PWVbeta $[\mathrm{m} / \mathrm{s}](r=0.202)$.

Conclusions: There is a link between arterial stiffness and subclinical inflammation in pediatric patients with primary hypertension. Neutrophil-to-lymphocyte ratio may serve as a promising marker of arterial stiffness in pediatric patients affected by primary hypertension.
\end{abstract}

Key words: children, primary hypertension, arterial stiffness, subclinical inflammation, neutrophilto-lymphocyte ratio, adolescents, pulse wave velocity.

(Cent J Eur Immunol 2021; 46 (3): 336-343)

\section{Introduction}

Arterial hypertension $(\mathrm{AH})$ is one of the most common clinical issues in adults, but also is becoming a serious health problem in the pediatric population. Primary hypertension $(\mathrm{PH})$ is the most common form of $\mathrm{AH}$ in adolescents. The prevalence of $\mathrm{PH}$ in children and the adolescent population is constantly growing, because of obesity, sedentary lifestyle, and excessive salt intake [1]. PH is a systemic disorder consisting of improper body composition and fatty tissue distribution, and finally activation of the immune system with early vascular aging [2].

In the last two decades the role of immune system activation in the pathogenesis of primary hypertension and in development of target-organ damage (TOD) has been extensively studied [3,4]. While the ultimate mechanism of immune involvement in the pathogenesis of hypertension is far from clear, there is no doubt that primary hypertension could be considered a state of subclinical inflammation [5]. A growing body of evidence further suggests the involvement of immune mechanisms in the development of negative arterial changes already in hypertensive children [6]. The extent of subclinical inflammation can be measured using e.g., concentration of pro-inflammatory cytokines but also with simple complete blood count (CBC)-derived markers such as neutrophil-to-lymphocyte ratio (NLR), platelet-to-lymphocyte ratio (PLR), and mean

Correspondence: Piotr Skrzypczyk, MD, PhD, Department of Pediatrics and Nephrology, Medical University of Warsaw,

e-mail: pskrzypczyk@wum.edu.pl

Submitted: 2.02.2021; Accepted: 15.06.2021 
platelet volume (MPV). In adults, elevated NLR, PLR and MPV were not only found in hypertensive patients and patients with acute coronary syndrome but also they were proposed as independent risk factors of mortality [7, 8].

In adults a relation between subclinical inflammation and arterial damage has already been revealed [9], whereas not much is known in children $[10,11]$. Thus, the aim of the study was to assess the relation between subclinical inflammation and subclinical arterial damage in pediatric patients with PH and to establish the usefulness of NLR, PLR, and MPV as markers of arterial damage in these subjects.

\section{Material and methods}

In this cross-sectional study we analyzed markers of subclinical inflammation and cardiovascular parameters in a group of 119 children with PH and 45 healthy, age- and sex-matched children. The inclusion criteria were: arterial hypertension diagnosed according to up-to-date Polish guidelines [1], and height $\geq 120 \mathrm{~cm}$. The exclusion criteria were: secondary arterial hypertension, coexisting cardiovascular or kidney diseases, chronic inflammatory diseases and acute infections, the latter being a temporary two-week exclusion.

The following clinical parameters were evaluated in all the participants: age (years), sex, duration of PH (months), medications that might affect cardiovascular system, height $(\mathrm{cm})$, weight $(\mathrm{kg})$, and body mass index $\left(\mathrm{BMI} ; \mathrm{kg} / \mathrm{m}^{2}\right)$. Anthropometric variables were expressed as $\mathrm{Z}$-scores calculated from national normative data [12]. In all the studied children a peripheral automated complete blood count was performed using a Coulter LH 780 hematologic analyzer (Sysmex XN1000, Sysmex Corporation, Kobe, Japan) and the following data were analyzed: direct numbers of neutrophils (NEU; $1000 / \mu 1)$, lymphocytes (LYM; 1000/ $\mu$ l), and platelets (PLT; 1000/ $\mu \mathrm{l})$, mean platelet volume (MPV; fl), NLR and PLR. Furthermore, basic laboratory parameters data were assessed: glomerular filtration rate (GFR) according to the Schwartz formula $\left(\mathrm{ml} / \mathrm{min} / 1.73 \mathrm{~m}^{2}\right)$ [13], uric acid (mg/dl), total, low-density lipoprotein (LDL), and high-density lipoprotein (HDL) cholesterol (mg/dl), and triglycerides (mg/dl). Hypercholesterolemia was defined as cholesterol $\geq 200 \mathrm{mg} / \mathrm{dl}$ and hypertriglyceridemia was diagnosed when the triglyceride level exceeded $100 \mathrm{mg} / \mathrm{dl}$ in children aged 0-9 years and $130 \mathrm{mg} / \mathrm{dl}$ in children aged 10-17 years [14]. Since no cut-off point to determine hyperuricemia in children was established, in reference to the studies on the pediatric population elevated uric acid level was taken as $\geq 5.5 \mathrm{mg} / \mathrm{dl}$ [15].

The methodology of blood pressure (BP) measurements and evaluation of arterial damage were described in detail in our previous manuscripts, and the method description partly reproduces their wording [16-19]. Office oscillometric blood pressure measurement was performed using Welch Allyn Vital Signs Monitor 300 (Welch Allyn Inc., Skaneateles Falls, NY, USA) and BP values were expressed as $\mathrm{mmHg}$ and Z-scores [20]. According to the American Heart Association guidelines [21] a SUNTECH OSCAR 2 device (SunTech Medical, Inc., Morrisville, NC, USA) was used to perform 24-hour blood pressure measurement. The following ambulatory blood pressure monitoring (ABPM) parameters were evaluated: systolic (SBP) and diastolic (DBP) blood pressure and mean arterial pressure (MAP) during 24 hours ( $\mathrm{mmHg}$ ), pulse pressure (PP) during 24 hours (mmHg), SBP and DBP load during 24 hours (\%), nocturnal blood pressure dip (\%), and ambulatory arterial stiffness index (AASI) calculated according to Staessen's methodology [22].

Arterial pulse waveform, central blood pressure and aortic (i.e., carotid-femoral) pulse wave velocity (aPWV) were estimated with a Sphygmocor device, AtCor Medical Pty Ltd., Sydney, Australia using applanation tonometry. aPWV was expressed as $\mathrm{m} / \mathrm{s}$ and as Z-score using pediatric normative data [23]. Carotid intima media thickness (cIMT) was measured by one investigator (PS) with a 13-MHz linear transducer, Aloka Prosound Alpha 6, Hitachi Aloka Medical, Mitaka, Japan, and expressed as $\mathrm{mm}$ and as Z-score [24]. Additionally, local stiffness of the common carotid artery was evaluated using the E-tracking option of the device mentioned above.

All procedures were performed in accordance with the Declaration of Helsinki on the treatment of human subjects and further amendments. The research project was approved by the local Ethics Committee (approval No. KB/58/2016). Informed consent was obtained from all participants ( $\geq 16$ years) and their representatives included in the study.

Statistical analysis was performed using TIBCO Statistica 13.3 PL software (TIBCO Software Inc., AlisoViejo, CA, USA). Variables were presented as the mean \pm standard deviation (SD) and interquartile range (IQR). Normality of data distribution was tested using the Shapiro-Wilk test. The following tests were used (depending on data distribution): Student $t$-test, Mann-Whitney $U$ test, Pearson linear correlation, Spearman rank correlation, and $\chi^{2}$ test. A $p$-value $<0.05$ was considered statistically significant.

\section{Results}

The clinical and laboratory characteristics of children included in the study are presented in Table 1 . The hypertensive and normotensive groups did not differ significantly in terms of age and sex, but both BMI and BMI Z-score were significantly higher in children with hypertension. In children with $\mathrm{PH}$ overweight was found in $37(31.1 \%)$ children; 22 (18.5\%) children were obese. Among 119 patients with PH 55 (46.2\%) patients received antihypertensive medications and $64(53.8 \%)$ patients were 
Table 1. Clinical and laboratory parameters in hypertensive and healthy children.

\begin{tabular}{|c|c|c|c|}
\hline Parameter & $\begin{array}{c}\text { Study group } \\
\quad n=119\end{array}$ & $\begin{array}{c}\text { Control group } \\
\qquad n=45\end{array}$ & $p$ \\
\hline Age (years) & $\begin{array}{c}14.9 \pm 2.8 \\
(13.8-16.8)\end{array}$ & $\begin{array}{c}14.9 \pm 2.7 \\
(13.8-17.2)\end{array}$ & 0.936 \\
\hline Sex (male/female) & $86 / 33$ & $27 / 18$ & 0.130 \\
\hline BMI & $\begin{array}{c}24.7 \pm 5.1 \\
(21.3-27.7)\end{array}$ & $\begin{array}{c}22.2 \pm 4.0 \\
(19.3-26.1)\end{array}$ & 0.003 \\
\hline BMI Z-score & $\begin{array}{l}1.0 \pm 1.0 \\
(0.3-1.9)\end{array}$ & $\begin{array}{c}0.5 \pm 0.9 \\
(-0.3-1.3)\end{array}$ & 0.008 \\
\hline $\begin{array}{l}\text { Pharmacological } \\
\text { treatment }\end{array}$ & $55(46.2 \%)$ & & \\
\hline $\begin{array}{l}\text { Calcium channel } \\
\text { antagonists }\end{array}$ & 30 & & \\
\hline $\begin{array}{l}\text { Angiotensin } \\
\text { converting enzyme } \\
\text { inhibitors }\end{array}$ & 16 & & \\
\hline$\beta$-adrenolytics & 4 & & \\
\hline $\begin{array}{l}\text { AT1 receptor } \\
\text { antagonists }\end{array}$ & 2 & & \\
\hline$\alpha$-adrenolytics & 1 & & \\
\hline Diuretics & 2 & & \\
\hline $\mathrm{NEU}\left(\times 10^{3} / \mu \mathrm{l}\right)$ & $\begin{array}{l}3.9 \pm 1.7 \\
(2.7-4.5) \\
\end{array}$ & $\begin{array}{l}3.0 \pm 1.0 \\
(2.2-3.3) \\
\end{array}$ & $<0.001$ \\
\hline $\mathrm{LYM}\left(\times 10^{3} / \mu \mathrm{l}\right)$ & $\begin{array}{l}2.2 \pm 0.8 \\
(1.8-2.5)\end{array}$ & $\begin{array}{l}2.3 \pm 0.7 \\
(1.9-2.6)\end{array}$ & 0.462 \\
\hline $\operatorname{PLT}\left(\times 10^{3} / \mu \mathrm{l}\right)$ & $\begin{array}{c}271.9 \pm 62.3 \\
(227-305) \\
\end{array}$ & $\begin{array}{c}250.3 \pm 60.3 \\
(217-280) \\
\end{array}$ & 0.047 \\
\hline NLR & $\begin{array}{l}1.9 \pm 1.5 \\
(1.2-2.1)\end{array}$ & $\begin{array}{l}1.3 \pm 0.4 \\
(1.0-1.5) \\
\end{array}$ & 0.010 \\
\hline PLR & $\begin{array}{c}131.4 \pm 41.9 \\
(106.7-148.6)\end{array}$ & $\begin{array}{l}114.7 \pm 37.6 \\
(86.3-136.6) \\
\end{array}$ & 0.020 \\
\hline MPV (fl) & $\begin{array}{c}10.6 \pm 1.1 \\
(10.0-11.2) \\
\end{array}$ & $\begin{array}{c}10.8 \pm 1.0 \\
(10.2-11.3) \\
\end{array}$ & 0.133 \\
\hline $\begin{array}{l}\text { GFR } \\
\left(\mathrm{ml} / \mathrm{min} / 1.73 \mathrm{~m}^{2}\right)\end{array}$ & $\begin{array}{l}100.1 \pm 21.7 \\
(84.9-113.6) \\
\end{array}$ & $\begin{array}{c}95.0 \pm 18.9 \\
(86.2-103.3)\end{array}$ & 0.307 \\
\hline Uric acid (mg/dl) & $\begin{array}{l}5.7 \pm 1.4 \\
(4.8-6.6) \\
\end{array}$ & $\begin{array}{l}5.0 \pm 1.3 \\
(4.0-5.9) \\
\end{array}$ & 0.011 \\
\hline $\begin{array}{l}\text { Total cholesterol } \\
(\mathrm{mg} / \mathrm{dl})\end{array}$ & $\begin{array}{c}157.9 \pm 32.5 \\
(136-171) \\
\end{array}$ & $\begin{array}{c}153.9 \pm 27.7 \\
(135-176) \\
\end{array}$ & 0.473 \\
\hline HDL (mg/dl) & $\begin{array}{c}50.9 \pm 12.2 \\
(44-56)\end{array}$ & $\begin{array}{c}54.6 \pm 12.2 \\
(48-60)\end{array}$ & 0.099 \\
\hline $\mathrm{LDL}$ (mg/dl) & $\begin{array}{c}87.4 \pm 29.9 \\
(68-99) \\
\end{array}$ & $\begin{array}{c}82.8 \pm 22.5 \\
(65-105)\end{array}$ & 0.366 \\
\hline $\begin{array}{l}\text { Triglycerides } \\
(\mathrm{mg} / \mathrm{dl})\end{array}$ & $\begin{array}{c}99.7 \pm 47.8 \\
(65-123)\end{array}$ & $\begin{array}{c}82.4 \pm 37.1 \\
(55-99)\end{array}$ & 0.035 \\
\hline
\end{tabular}

BMI - body mass index, ATI - angiotensin II receptor type 1, NEU - neutrophils, LYM - lymphocytes, PLT-platelets, NLR - neutrophil-to-lymphocyte ratio, PLR - platelet-to-lymphocyte ratio, MPV - mean platelet volume, GFR - glomerular filtration rate, $H D L$ - high-density lipoprotein, $L D L-l o w-$ density lipoprotein treatment-naive subjects. In the subgroup of subjects on antihypertensive drugs the most commonly administered medications were calcium channel antagonists, and the second most common medication group was angiotensin-converting enzyme inhibitors. Hypertensive patients

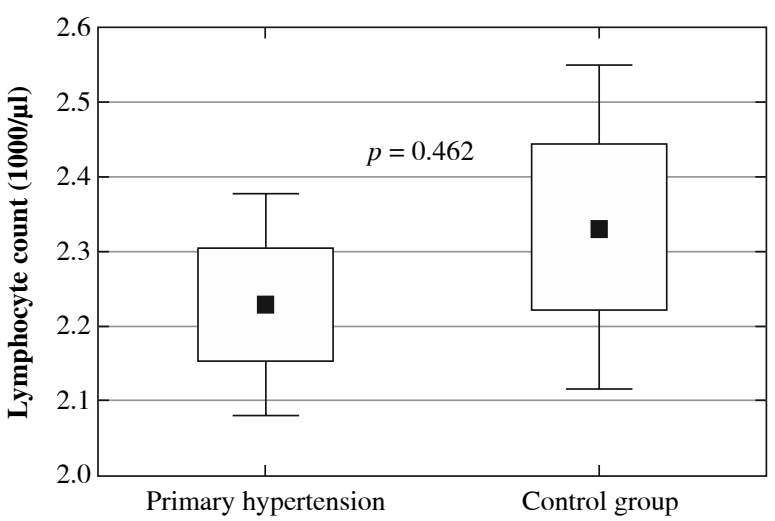

Fig. 1. Lymphocytes in children with primary hypertension and in healthy children

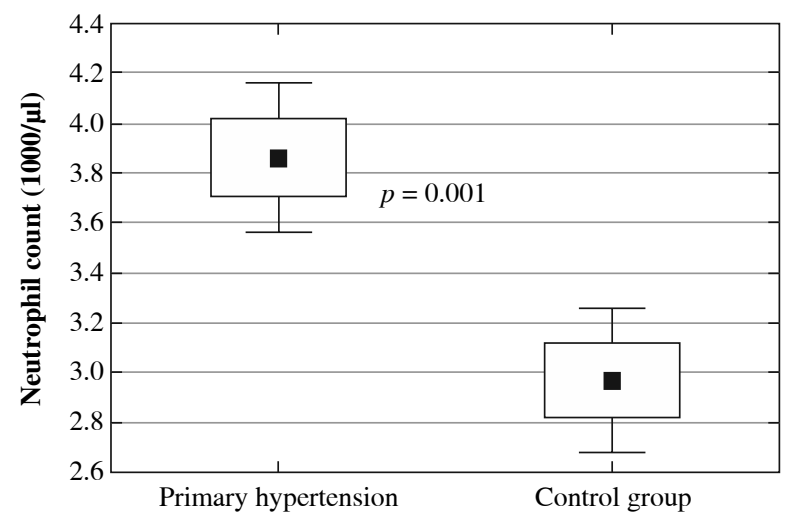

Fig. 2. Neutrophils in children with primary hypertension and in healthy children

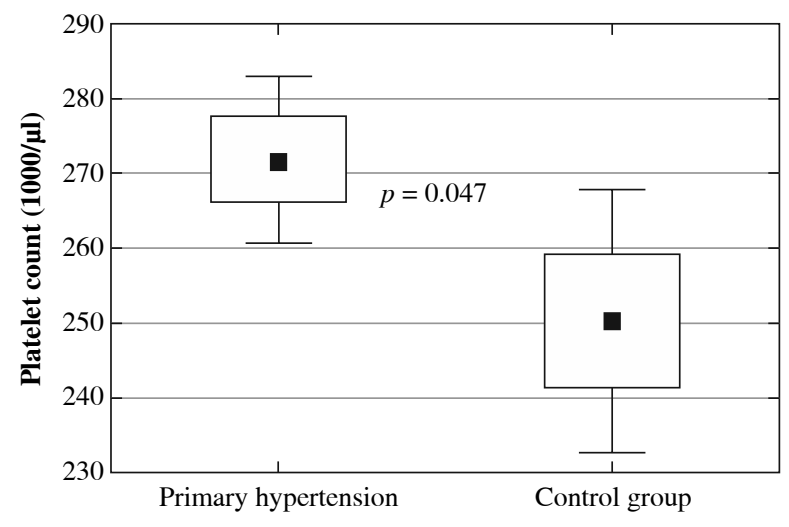

Fig. 3. Platelets in children with primary hypertension and in healthy children 


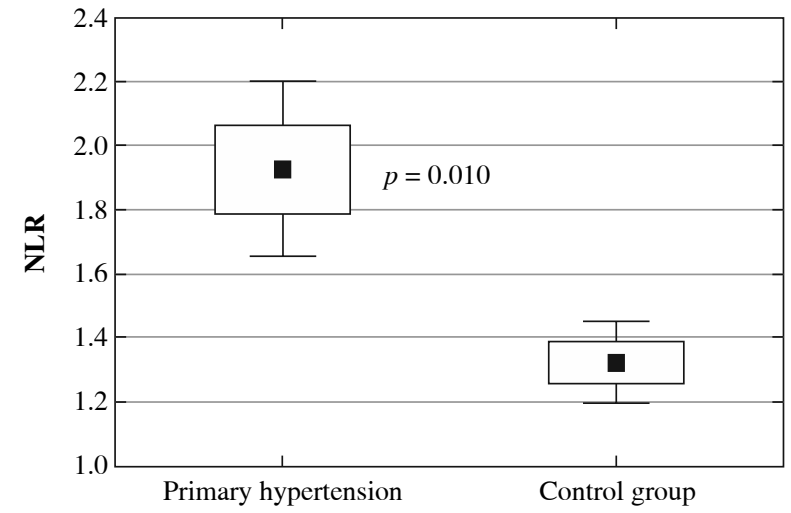

Fig. 4. Neutrophil-to-lymphocyte ratio (NLR) in children with primary hypertension and in healthy children

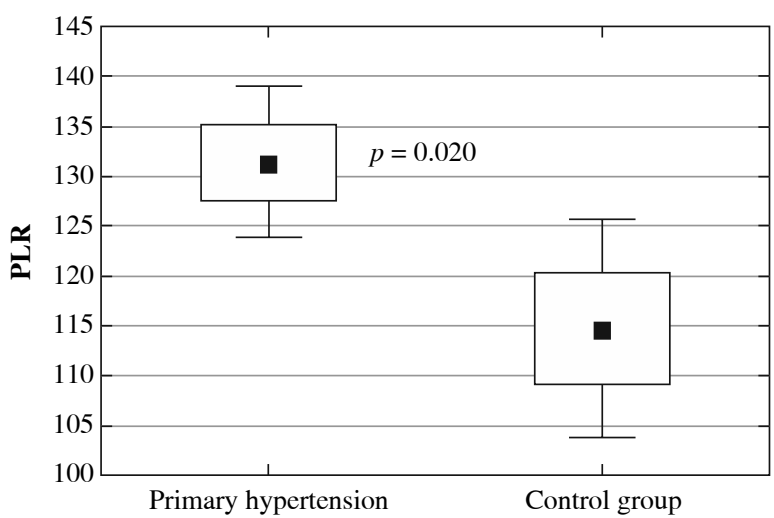

Fig. 5. Platelet-to-lymphocyte ratio (PLR) in children with primary hypertension and in healthy children

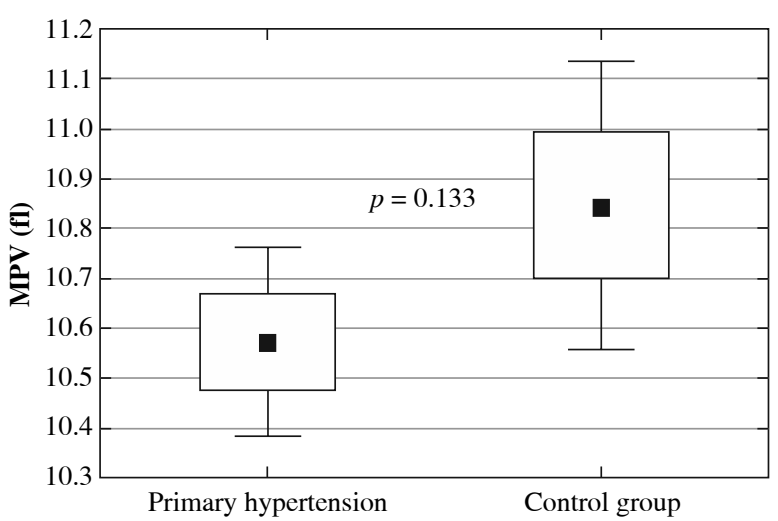

Fig. 6. Mean platelet volume (MPV) in children with primary hypertension and in healthy children

were characterized by significantly higher neutrophil and platelet count, higher neutrophil-to-lymphocyte ratio, and platelet-to-lymphocyte ratio. No differences were found in lymphocyte count and mean platelet volume (Fig. 1). Hypercholesterolemia, hypertriglyceridemia, and hyperuricemia were revealed in $8(6.7 \%), 7(5.9 \%)$, and $45(37.8 \%)$
Table 2. Blood pressure in children with primary hypertension and in the control group

\begin{tabular}{|c|c|c|c|}
\hline Parameter & $\begin{array}{c}\text { Study group } \\
n=119\end{array}$ & $\begin{array}{c}\text { Control group } \\
\quad n=45\end{array}$ & $p$ \\
\hline $\mathrm{SBP}(\mathrm{mmHg})$ & $\begin{array}{c}132.3 \pm 12.2 \\
(124-142)\end{array}$ & $\begin{array}{c}122.0 \pm 10.8 \\
(112-130)\end{array}$ & $<0.001$ \\
\hline $\mathrm{DBP}(\mathrm{mmHg})$ & $\begin{array}{c}77.3 \pm 10.1 \\
(71-83)\end{array}$ & $\begin{array}{c}71.7 \pm 8.6 \\
(67-78)\end{array}$ & $<0.001$ \\
\hline AoSBP (mmHg) & $\begin{array}{c}110.4 \pm 10.0 \\
(104-117)\end{array}$ & $\begin{array}{c}101.5 \pm 9.0 \\
(95-107)\end{array}$ & $<0.001$ \\
\hline AoDBP (mmHg) & $\begin{array}{c}79.1 \pm 10.2 \\
(72-84) \\
\end{array}$ & $\begin{array}{c}73.1 \pm 8.6 \\
(69-80)\end{array}$ & $<0.001$ \\
\hline AoMAP (mmHg) & $\begin{array}{l}94.1 \pm 9.7 \\
(87-100)\end{array}$ & $\begin{array}{c}87.1 \pm 8.3 \\
(83-92)\end{array}$ & $<0.001$ \\
\hline $24 \mathrm{~h} \mathrm{SBP}(\mathrm{mmHg})$ & $\begin{array}{c}130.8 \pm 8.7 \\
(124-137)\end{array}$ & $\begin{array}{l}122.3 \pm 5.1 \\
(116-126)\end{array}$ & $<0.001$ \\
\hline 24 h DBP (mmHg) & $\begin{array}{c}71.2 \pm 6.9 \\
(67-76)\end{array}$ & $\begin{array}{c}68.7 \pm 3.4 \\
(66-71)\end{array}$ & 0.091 \\
\hline 24 h MAP (mmHg) & $\begin{array}{c}91.0 \pm 6.8 \\
(86-96)\end{array}$ & $\begin{array}{c}86.7 \pm 3.2 \\
(84-90)\end{array}$ & 0.003 \\
\hline $24 \mathrm{~h}$ MAP Z-score & $\begin{array}{l}1.3 \pm 1.4 \\
(0.5-2.0)\end{array}$ & $\begin{array}{l}0.4 \pm 0.5 \\
(0.0-0.9)\end{array}$ & $<0.002$ \\
\hline 24 h SBPL (\%) & $\begin{array}{c}46.9 \pm 24.6 \\
(30-64)\end{array}$ & $\begin{array}{c}17.3 \pm 11.2 \\
(10-25)\end{array}$ & $<0.001$ \\
\hline 24 h DBPL (\%) & $\begin{array}{l}23.2 \pm 19.2 \\
(9-29)\end{array}$ & $\begin{array}{c}12.9 \pm 8.8 \\
(7-17)\end{array}$ & 0.013 \\
\hline SBP DIP $(\%)$ & $\begin{array}{l}10.9 \pm 5.1 \\
(8.0-13.6)\end{array}$ & $\begin{array}{l}11.2 \pm 4.1 \\
(7.7-14.1)\end{array}$ & 0.793 \\
\hline DBP DIP $(\%)$ & $\begin{array}{c}15.9 \pm 7.5 \\
(11.2-20.1)\end{array}$ & $\begin{array}{c}14.1 \pm 6.4 \\
(10.5-17.6)\end{array}$ & 0.287 \\
\hline AASI & $\begin{array}{l}0.38 \pm 0.12 \\
(0.32-0.45)\end{array}$ & $\begin{array}{l}0.38 \pm 0.10 \\
(0.28-0.47)\end{array}$ & 0.909 \\
\hline
\end{tabular}

$S B P$ - systolic blood pressure, DBP - diastolic blood pressure, AoSBP - central (aortic) systolic blood pressure, AoDBP - central (aortic) diastolic blood pressure, AoMAP - central (aortic) mean arterial pressure, MAP - mean arterial pressure, $S B P L-$ systolic blood pressure load, $D B P L$ - diastolic blood pressure load, SBP DIP - night-time systolic blood pressure dip, DBP DIP - night-time diastolic blood pressure dip, AASI - ambulatory arterial stiffness index

patients with primary hypertension, respectively. Hypertensive patients had significantly higher uric acid and triglycerides compared to healthy peers.

The results of ABPM measurement are depicted in Table 2. Patients with $\mathrm{PH}$ were characterized by significantly higher office peripheral and central blood pressure. SBP and MAP, but not DBP, measured by ABPM, were also significantly higher in $\mathrm{PH}$ patients compared to healthy peers. The two groups did not differ in terms of circadian rhythm and arterial stiffness indirectly evaluated as AASI. Table 3 shows parameters of subclinical target organ damage. Patients with $\mathrm{PH}$ were characterized by higher aPWV, aPWV Z-score, cIMT, cIMT Z-score, and common carotid artery maximal diameter derived from Echo-tracking measurement, when compared to normotensive peers. 
Table 3. Arterial parameters in the study and the control group

\begin{tabular}{|c|c|c|c|}
\hline Parameter & $\begin{array}{c}\text { Study group } \\
\quad n=119\end{array}$ & $\begin{array}{c}\text { Control group } \\
\quad n=45 \\
\end{array}$ & $p$ \\
\hline AIx75HR (\%) & $\begin{array}{l}-2.9 \pm 12.2 \\
(-10.0-3.7)\end{array}$ & $\begin{array}{l}-3.6 \pm 11.7 \\
(-10.3-2.0)\end{array}$ & 0.744 \\
\hline SEVR (\%) & $\begin{array}{c}162.4 \pm 38.2 \\
(134-185)\end{array}$ & $\begin{array}{c}159.5 \pm 29.8 \\
(137.0-172.3)\end{array}$ & 0.648 \\
\hline $\mathrm{aPWV}(\mathrm{m} / \mathrm{s})$ & $\begin{array}{l}5.36 \pm 0.88 \\
(4.73-6.05)\end{array}$ & $\begin{array}{l}4.88 \pm 0.92 \\
(4.27-5.35)\end{array}$ & 0.004 \\
\hline aPWV Z-score & $\begin{array}{c}0.26 \pm 1.49 \\
(-0.92-1.29)\end{array}$ & $\begin{array}{c}-0.60 \pm 1.61 \\
(-2.10-0.271)\end{array}$ & 0.002 \\
\hline $\operatorname{cIMT}(\mathrm{mm})$ & $\begin{array}{l}0.46 \pm 0.07 \\
(0.41-0.51)\end{array}$ & $\begin{array}{c}0.43 \pm 0.07 \\
(0.4-0.5)\end{array}$ & 0.002 \\
\hline cIMT Z-score & $\begin{array}{c}1.50 \pm 1.44 \\
(0.47-2.44)\end{array}$ & $\begin{array}{c}0.73 \pm 1.26 \\
(-0.16-1.23)\end{array}$ & 0.002 \\
\hline ET beta & $\begin{array}{l}3.6 \pm 2.5 \\
(2.4-4.1)\end{array}$ & $\begin{array}{l}3.5 \pm 1.0 \\
(2.8-4.3)\end{array}$ & 0.894 \\
\hline ET Ep (kPa) & $\begin{array}{c}48.3 \pm 33.2 \\
(31-55) \\
\end{array}$ & $\begin{array}{c}44.2 \pm 12.7 \\
(35-55)\end{array}$ & 0.428 \\
\hline ET AC $\left(\mathrm{mm}^{2} / \mathrm{kPa}\right)$ & $\begin{array}{l}1.3 \pm 0.5 \\
(1.0-1.5)\end{array}$ & $\begin{array}{l}1.1 \pm 0.4 \\
(0.9-1.3)\end{array}$ & 0.043 \\
\hline ET AIx (\%) & $\begin{array}{l}-2.9 \pm 18.8 \\
(-9.7-0.3)\end{array}$ & $\begin{array}{l}-2.5 \pm 8.8 \\
(-7.7-0.6)\end{array}$ & 0.902 \\
\hline ET PWVbeta $(\mathrm{m} / \mathrm{s})$ & $\begin{array}{l}4.0 \pm 1.1 \\
(3.4-4.4)\end{array}$ & $\begin{array}{l}3.9 \pm 0.6 \\
(3.5-4.4)\end{array}$ & 0.628 \\
\hline ET Dmax (mm) & $\begin{array}{l}6.5 \pm 0.7 \\
(6.0-6.9)\end{array}$ & $\begin{array}{l}6.0 \pm 0.7 \\
(5.5-6.6)\end{array}$ & 0.001 \\
\hline ET Dmin (mm) & $\begin{array}{l}6.0 \pm 5.7 \\
(5.0-6.0)\end{array}$ & $\begin{array}{l}5.2 \pm 0.7 \\
(4.7-5.7)\end{array}$ & 0.321 \\
\hline ET DATmax (ms) & $\begin{array}{c}133.2 \pm 38.5 \\
(107-142)\end{array}$ & $\begin{array}{c}142.6 \pm 41.1 \\
(120-148)\end{array}$ & 0.185 \\
\hline
\end{tabular}

AIx75HR - augmentation index corrected for heart rates, SEVR - subendocardial viability ratio, aPWV-aortic pulse wave velocity, cIMT - carotid intima media thickness, ET-E-tracking, beta-stiffness index, Ep-pressure strain elasticity modulus, AC-arterial compliance, AIx-augmentation index, $P W V b e t a-c o m m o n$ carotid artery pulse wave velocity, Dmax - maximal diameter of the artery, Dmin-minimal diameter of the artery, DATmax-acceleration time to artery maximal diameter

Correlations of blood pressure, parameters of arterial damage, and inflammatory indicators in children with $\mathrm{PH}$ are presented in Table 4. In the group of 119 children with $\mathrm{PH}$ we found positive correlations between NLR and office SBP, 24 h ABPM: SBP, DBP, MAP, MAP Z-score and both SBP and DBP load. Also, a positive correlation between PLR and heart rate derived from 24-hour ABPM was revealed. In our study PLR showed a significant negative correlation with subendocardial viability ratio (SEVR). Statistical analysis revealed that NLR correlated positively with aPWV, aPWV Z-score and both elastic modulus (Ep) and local PWV measured on carotid artery using the echo-tracking method. There were no statistically significant correlations between MPV, blood pres- sure and measured arterial stiffness parameters. As for healthy children, NLR correlated positively only with office SBP Z-score $(R=0.517, p=0.002)$ and DBP Z-score $(R=0.498, p=0.003)$. No significant correlations between NLR, PLR, MPV, and age were revealed in hypertensive and healthy children.

\section{Discussion}

In our single center cross-sectional study, we found that markers of subclinical inflammation, i.e., NLR and PLR, and platelet count, were significantly higher in hypertensive patients compared to healthy peers. Moreover, NLR correlated positively with numerous indices of blood pressure measured in ABPM and with arterial stiffness measured with different methodological approaches and in two different vascular regions.

Our pediatric patients with primary hypertension were characterized by significantly faster aortic and carotid pulse wave velocity, thicker intima media, and higher maximal diameter of common carotid artery, when compared with healthy peers. Arteriosclerotic changes are already seen in children affected with elevated blood pressure. These lesions are at least partially compensative adaptations to increased blood pressure strain [25]. Increased aortic [26] and local arterial stiffness [27], as well as increased carotid artery diameter [27] and cIMT [27, 28], had already been found in $\mathrm{PH}$ pediatric patients by other authors. The measurement of subclinical arterial lesions is recommended by 2016 pediatric guidelines of the European Society of Hypertension (ESH) as accessory evaluation of hypertensive target-organ damage [29]. Although we still lack studies linking subclinical TOD in children and hard endpoints in adults, recent meta-analyses proved that measurement of both cIMT [30] and aortic PWV [31] are useful and accurate cardiovascular mortality predictors in the adult population.

The idea of the role of the immune system in the pathogenesis of primary hypertension is certainly not a new concept. In 1960s Okuda and Grollmann found that transfer of lymphocytes from rats with renal infarction induced arterial hypertension in recipient, previously normotensive animals [32]. Moreover, in 1972 Olsen described the perivascular infiltration of $\mathrm{T}$ cells and monocytes in adults with different forms of arterial hypertension [33]. In the last two decades, experimental studies have revealed numerous pathophysiological pathways linking activation of both the innate and the acquired immune system, blood pressure elevation, and target-organ damage. Current hypotheses combine the role of salt and immune system activation. Prohypertensive stimuli such as salt and shear stress enhance polarization of naive $\mathrm{T}$ cells towards a proinflammatory Th17 phenotype, enhance production of inflammatory cytokines and reactive oxygen species, weaken activation of anti-inflammatory macrophages, and 
Table 4. Correlations of blood pressure with markers of subclinical inflammation derived from full blood count in children with primary hypertension

\begin{tabular}{|c|c|c|c|}
\hline Analyzed parameters & NLR & PLR & MPV \\
\hline \multicolumn{4}{|c|}{ Blood pressure } \\
\hline $\mathrm{SBP}(\mathrm{mmHg})$ & $R=0.230, p=0.020$ & $R=0.114, p=0.251$ & $R=0.141, p=0.154$ \\
\hline 24 h SBP (mmHg) & $R=0.243, p=0.012$ & $R=-0.034, p=0.729$ & $R=0.045, p=0.646$ \\
\hline 24 h DBP (mmHg) & $R=0.216, p=0.027$ & $R=0.082, p=0.406$ & $R=0.133, p=0.178$ \\
\hline 24 h MAP $(\mathrm{mmHg})$ & $R=0.251, p=0.010$ & $R=0.029, p=0.767$ & $R=0.118, p=0.232$ \\
\hline $24 \mathrm{~h}$ MAP Z-score & $R=0.242, p=0.013$ & $R=0.081, p=0.411$ & $R=0.103, p=0.298$ \\
\hline 24 h SBPL (\%) & $R=0.245, p=0.012$ & $R=-0.010, p=0.917$ & $R=0.070, p=0.481$ \\
\hline 24 h DBPL (\%) & $R=0.243, p=0.013$ & $R=0.068, p=0.491$ & $R=0.003, p=0.978$ \\
\hline 24 h HR (bpm) & $R=0.175, p=0.073$ & $R=0.211, p=0.031$ & $R=-0.016, p=0.870$ \\
\hline \multicolumn{4}{|c|}{ Arterial parameters } \\
\hline AIx75HR (\%) & $R=0.019, p=0.842$ & $R=-0.002, p=0.981$ & $R=0.080, p=0.401$ \\
\hline $\operatorname{SEVR}(\%)$ & $R=-0.181, p=0.052$ & $R=-0.372, p<0.001$ & $R=-0.027, p=0.775$ \\
\hline $\mathrm{aPWV}(\mathrm{m} / \mathrm{s})$ & $R=0.241, p=0.012$ & $R=0.051, p=0.598$ & $R=0.143, p=0.139$ \\
\hline aPWV Z-score & $R=0.204, p=0.034$ & $R=0.062, p=0.522$ & $R=0.131, p=0.176$ \\
\hline cIMT (mm) & $R=0.098, p=0.309$ & $R=-0.038, p=0.695$ & $R=0.129, p=0.180$ \\
\hline cIMT Z-score & $R=0.076, p=0.429$ & $R=-0.036, p=0.706$ & $R=0.129, p=0.179$ \\
\hline ET Ep $(\mathrm{kPa})$ & $R=0.197, p=0.040$ & $R=0.058, p=0.552$ & $R=0.035, p=0.718$ \\
\hline ET PWVbeta (m/s) & $R=0.202, p=0.035$ & $R=0.045, p=0.639$ & $R=0.044, p=0.648$ \\
\hline
\end{tabular}

SBP-systolic blood pressure, DBP-diastolic blood pressure, MAP - mean arterial pressure, SBPL - systolic blood pressure load, DBPL - diastolic blood pressure load, HR - heart rate, AIx75HR - augmentation index corrected for heart rate of 75 beats per minute, SEVR - subendocardial viability ratio, aPWV - aortic pulse wave velocity, cIMT

impair immunosuppressive function of regulatory $\mathrm{T}$ lymphocytes (Tregs). Additionally, salt and increased tonus of the sympathetic system result in activation and migration of renal dendritic cells $[4,34]$. Activated immune cells produce reactive oxygen species (ROS) and proinflammatory cytokines, e.g., interleukin 17 , which, in the absence of the inhibiting influence of Tregs, exacerbate sodium retention, vasoconstriction and further rise in blood pressure. Similar interplay was observed within the arterial wall. Aldosterone, angiotensin II, and shear stress promote endothelial activation and damage with increased surface expression of adhesion molecules, i.e. selectins, as well as intercellular and vascular adhesion molecules, which facilitate immune cell recruitment into the vascular wall. Activated $\mathrm{T}$ cells, macrophages, and neutrophils increase vascular production of ROS, metalloproteinases, and transforming growth factor $\beta$. All these phenomena promote endothelial dysfunction, arterial stiffness, and decreased vascular flow, and perpetuate the cycle of inflammation and renin-angiotensin-aldosterone system activation [35-37].

Neutrophil-to-lymphocyte and platelet-to-lymphocyte ratios were found to be inexpensive, reproducible markers of a systemic inflammatory response. Adult studies have shown that both high NLR [7] and PLR [8] are associated with poor clinical outcomes in various cardiovascular diseases. Both these markers were found to be significantly higher in our pediatric group of hypertensive children compared to normotensive individuals, which can suggest a higher grade of inflammation in comparison with healthy peers. In addition, in hypertensive patients NLR value correlated positively with blood pressure in both office and ABPM measurements. Notably, we excluded patients with chronic inflammatory conditions (e.g. juvenile idiopathic arthritis) and acute infections (e.g. influenza). Similarly, higher values of NLR were found in two studies on adults with arterial hypertension [38, 39]. Moreover, Chinese authors found that higher NLR was a predictor of development of hypertension in a 6-year-observation [40]. All these results suggest that NLR could be utilized as an early predictive tool to implement intervention aimed at slowing the progression of the hypertensive process.

As already mentioned, experimental data indicate a direct relation between activation of the immune system and arterial damage. Positive correlations between arterial stiffness and markers of subclinical inflammation - high-sensitivity C-reactive protein (hsCRP), interleukin 6 (IL-6), interleukin $1 \beta$ (IL-1 $\beta$ ), monocyte chemoattractant protein-1 (MCP-1), and tumor necrosis factor $\alpha$ (TNF- $\alpha$ ) - have already been found in adults with primary hypertension [9, 41-43]. Also NLR was revealed as a marker of arteri- 
al stiffness in both healthy adults [44] and in adults with increased cardiovascular risk: those with arterial hypertension [45], diabetes mellitus type 1 [46] and type 2 [47], end-stage renal disease treated with peritoneal dialysis [48], and postmenopausal women with osteoporosis [49]. The same relation was found in our hypertensive patients for both aortic (carotid-femoral) and local, common carotid artery pulse wave velocity. To the best of our knowledge, this is the first study to demonstrate the positive relation between NLR and arterial stiffness in children. This is also the first study to reveal this dependence on the level of common carotid artery.

Notably, carotid-femoral PWV measures mainly aortic stiffness, i.e., stiffness of the largest artery, whereas E-tracking evaluates local elastic properties in the right common carotid artery. The aorta is an elastic vessel, whereas the carotid arteries are musculoelastic ones [50, 51]. In our study different methodological approaches were used to measure the elastic properties of these two vascular beds. Aortic elasticity was measured using applanation tonometry, considered to be the gold standard for measuring arterial stiffness, and E-tracking together with B-mode ultrasonography was used for common carotid artery stiffness [52]. In our hypertensive patients both aortic and local PWV were positively correlated with NLR. These results may suggest that the intramural inflammatory process in primary hypertension affects multiple arteries already in childhood.

Several limitations of our study need to be emphasized. First limitation is the cross-sectional character of our study. Secondly, indicators of subclinical inflammation were assessed using only CBC-derived indirect markers, i.e., NLR, PLR and MPV. On the other hand, the relatively large patient group and deep analysis of blood pressure and arterial damage are particular strengths of the study.

\section{Conclusions}

There is a relation between arterial stiffness and subclinical inflammation in pediatric patients with primary hypertension.

Neutrophil-to-lymphocyte ratio may serve as a robust marker of arterial stiffness in pediatric patients affected by primary hypertension.

The authors declare no conflict of interest.

\section{References}

1. Litwin M, Niemirska A, Obrycki Ł, et al. (2018): Guidelines of the Pediatric Section of the Polish Society of Hypertension on diagnosis and treatment of arterial hypertension in children and adolescents. Arterial Hypertension 22: 45-73.

2. Litwin M, Feber J, Niemirska A, Michałkiewicz J (2016): Primary hypertension is a disease of premature vascular aging associated with neuro-immuno-metabolic abnormalities. Pediatr Nephrol 31: 185-194.
3. Drummond GR, Vinh A, Guzik TJ, Sobey CG (2019): Immune mechanisms of hypertension. Nat Rev Immunol 19: 517-532.

4. Norlander AE, Madhur MS, Harrison DG (2018): The immunology of hypertension. J Exp Med 215: 21-33.

5. Litwin M, Michałkiewicz J, Niemirska A, et al. (2010): Inflammatory activation in children with primary hypertension. Pediatr Nephrol 25: 1711-1718.

6. Gackowska L, Michałkiewicz J, Niemirska A, et al. (2018): Loss of CD31 receptor in CD4+ and CD8+ T-cell subsets in children with primary hypertension is associated with hypertension severity and hypertensive target organ damage. J Hypertens 36: 2148-2156.

7. Bhat T, Teli S, Rijal J, et al. (2013): Neutrophil to lymphocyte ratio and cardiovascular diseases: a review. Expert Rev Cardiovasc Ther 11: 55-59.

8. Kurtul A, Ornek E (2019): Platelet to lymphocyte ratio in cardiovascular diseases: a systematic review. Angiology 70 : 802-818.

9. Mahmud A, Feely J (2005): Arterial stiffness is related to systemic inflammation in essential hypertension. Hypertension 46: $1118-1122$.

10. Glowinska B, Urban M, Peczynska J, Florys B (2005): Soluble adhesion molecules (sICAM-1, sVCAM-1) and selectins (sE selectin, $\mathrm{sP}$ selectin, $\mathrm{sL}$ selectin) levels in children and adolescents with obesity, hypertension, and diabetes. Metabolism 54: 1020-1026.

11. Garanty-Bogacka B, Syrenicz M, Syrenicz A, et al. (2005): Serum markers of inflammation and endothelial activation in children with obesity-related hypertension. Neuro Endocrinol Lett 26: 242-246.

12. Kułaga Z, Litwin M, Tkaczyk M, et al. (2011): Polish 2010 growth references for school-aged children and adolescents. Eur J Pediatr 170: 599-609.

13. Schwartz GJ, Muńoz A, Schneider MF, et al. (2009): New equations to estimate GFR in children with CKD. J Am Soc Nephrol 20: 629-637.

14. Expert Panel on Integrated Guidelines for Cardiovascular Health and Risk Reduction in Children and Adolescents; National Heart, Lung, and Blood Institute (2011): Expert panel on integrated guidelines for cardiovascular health and risk reduction in children and adolescents: summary report. Pediatrics 128 Suppl 5: S213-256.

15. Feig DI, Kang DH, Johnson RJ (2008): Uric acid and cardiovascular risk. N Engl J Med 359: 1811-1821.

16. Skrzypczyk P, Okarska-Napierała M, Stelmaszczyk-Emmel A, et al. (2019): Renalase in children with chronic kidney disease. Biomarkers 24: 638-644.

17. Skrzypczyk P, Przychodzień J, Mizerska-Wasiak M, et al. (2019): Asymmetric dimethylarginine is not a marker of arterial damage in children with glomerular kidney diseases. Cent Eur J Immunol 44: 370-379.

18. Skrzypczyk P, Ozimek A, Ofiara A, et al. (2019): Markers of endothelial injury and subclinical inflammation in children and adolescents with primary hypertension. Cent Eur J Immunol 44: 253-261.

19. Skrzypczyk P, Ofiara A, Szyszka M, et al. (2018): Vitamin D in children with primary hypertension. Arterial Hypertension 22: 127-134.

20. Kułaga Z, Litwin M, Grajda A, et al. (2012): Oscillometric blood pressure percentiles for Polish normal-weight schoolaged children and adolescents. J Hypertens 30: 1942-1954. 
21. Flynn JT, Daniels SR, Hayman LL, et al. (2014): Update: ambulatory blood pressure monitoring in children and adolescents: a scientific statement from the American Heart Association. Hypertension 63: 1116-1135.

22. Li Y, Wang JG, Dolan E, et al. (2006): Ambulatory arterial stiffness index derived from 24-hour ambulatory blood pressure monitoring. Hypertension 47: 359-364.

23. Reusz GS, Cseprekal O, Temmar M, et al. (2010): Reference values of pulse wave velocity in healthy children and teenagers. Hypertension 56: 217-224.

24. Doyon A, Kracht D, Bayazit AK, et al. (2013): Carotid artery intima-media thickness and distensibility in children and adolescents: reference values and role of body dimensions. Hypertension 62: 550-556.

25. Litwin M, Niemirska A (2009): Intima-media thickness measurements in children with cardiovascular risk factors. Pediatr Nephrol 24: 707-719.

26. Stergiou GS, Kollias A, Giovas PP, et al. (2010): Ambulatory arterial stiffness index, pulse pressure and pulse wave velocity in children and adolescents. Hypertens Res 33: 1272-1277.

27. Litwin M, Trelewicz J, Wawer Z, et al. (2004): Intima-media thickness and arterial elasticity in hypertensive children: controlled study. Pediatr Nephrol 19: 767-774.

28. Day TG, Park M, Kinra S (2017): The association between blood pressure and carotid intima-media thickness in children: a systematic review. Cardiol Young 27: 1295-1305.

29. Lurbe E, Agabiti-Rosei E, Cruickshank JK, et al. (2016): 2016 European Society of Hypertension guidelines for the management of high blood pressure in children and adolescents. J Hypertens 34: 1887-1920.

30. Willeit P, Tschiderer L, Allara E, et al. (2020): Carotid intima-media thickness progression as surrogate marker for cardiovascular risk: meta-analysis of 119 clinical trials involving 100667 patients. Circulation 142: 621-642.

31. Sequí-Domínguez I, Cavero-Redondo I, Álvarez-Bueno C, et al. (2020): Accuracy of pulse wave velocity predicting cardiovascular and all-cause mortality. a systematic review and meta-analysis. J Clin Med 9: 2080.

32. White FN, Grollman A (1964): autoimmune factors associated with infarction of the kidney. Nephron 1: 93-102.

33. Olsen F (1972): Inflammatory cellular reaction in hypertensive vascular disease in man. Acta Pathol Microbiol Scand A 80: 253-256.

34. Rucker AJ, Rudemiller NP, Crowley SD (2018): Salt, hypertension, and immunity. Annu Rev Physiol 80: 283-307.

35. Zhang RM, McNerney KP, Riek AE, Bernal-Mizrachi C (2021): Immunity and hypertension. Acta Physiol (Oxf) 231: e13487.

36. McMaster WG, Kirabo A, Madhur MS, Harrison DG (2015): Inflammation, immunity, and hypertensive end-organ damage. Circ Res 116: 1022-1033.

37. Jain S, Khera R, Corrales-Medina VF, et al. (2014): Inflammation and arterial stiffness in humans. Atherosclerosis 237: 381-390.

38. Jhuang YH, Kao TW, Peng TC, et al. (2019): Neutrophil to lymphocyte ratio as predictor for incident hypertension: a 9-year cohort study in Taiwan. Hypertens Res 42: 1209-1214.

39. Srinivasagopalane B, Andrew Rajarathinam S, Balasubramaiyan T (2019): Clinical pertinence of neutrophil-to-lymphocyte ratio among hypertensives with different grades and duration of hypertension - an insight. Clin Exp Hypertens 41: 394-399.

40. Liu X, Zhang Q, Wu H, et al. (2015): Blood neutrophil to lymphocyte ratio as a predictor of hypertension. Am J Hypertens 28: 1339-1346.
41. Gökaslan S, Özer Gökaslan Ç, Demirel E, Çelik S (2019): Role of aortic stiffness and inflammation in the etiology of young-onset hypertension. Turk J Med Sci 49: 1748-1753.

42. Pietri P, Vyssoulis G, Vlachopoulos C, et al. (2006): Relationship between low-grade inflammation and arterial stiffness in patients with essential hypertension. J Hypertens 24: 22312238.

43. Barbaro NR, Fontana V, Modolo R, et al. (2015): Increased arterial stiffness in resistant hypertension is associated with inflammatory biomarkers. Blood Press 24: 7-13.

44. Park BJ, Shim JY, Lee HR, et al. (2011): Relationship of neutrophil-lymphocyte ratio with arterial stiffness and coronary calcium score. Clin Chim Acta 412: 925-929.

45. Wang H, Hu Y, Geng Y, et al. (2017): The relationship between neutrophil to lymphocyte ratio and artery stiffness in subtypes of hypertension. J Clin Hypertens (Greenwich) 19: 780-785.

46. Ayhan H, Kasapkara HA, Aslan AN, et al. (2015): Relationship of neutrophil-to-lymphocyte ratio with aortic stiffness in type 1 diabetes mellitus. Can J Diabetes 39: 317-321.

47. Wang RT, Zhang JR, Li Y, et al. (2015): Neutrophil-lymphocyte ratio is associated with arterial stiffness in diabetic retinopathy in type 2 diabetes. J Diabetes Complications 29: 245-249.

48. Cai K, Luo Q, Zhu B, et al. (2016): Neutrophil-lymphocyte ratio is associated with arterial stiffness in patients with peritoneal dialysis. BMC Nephrol 17: 191.

49. Yu XY, Li XS, Li Y, et al. (2015): Neutrophil-lymphocyte ratio is associated with arterial stiffness in postmenopausal women with osteoporosis. Arch Gerontol Geriatr 61: 76-80.

50. Sethi S, Rivera O, Oliveros R, Chilton R (2014): Aortic stiffness: pathophysiology, clinical implications, and approach to treatment. Integr Blood Press Control 7: 29-34.

51. Bruno RM, Cartoni G, Stea F, et al. (2017): Carotid and aortic stiffness in essential hypertension and their relation with target organ damage: the CATOD study. J Hypertens 35: 310-318.

52. Skrzypczyk P, Pańczyk-Tomaszewska M (2017): Methods to evaluate arterial structure and function in children - state-ofthe art knowledge. Adv Med Sci 62: 280-294. 